\section{Incentive and frustration effect of direct goal placements}

\author{
JOHN J. PORTER, HARRY L. MADISON, and ALAN J. SWATEK \\ University of Wisconsin-Milwaukee, Milwaukee, Wis. 53201
}

Effects of rewarded direct goalbox placements (DPs) prior to runway training on first-trial acquisition and resistance to extinction were studied. DPs directly over the foodcup enhanced first-trial performance, but did not produce an overlearning-extinction effect (OLE). DPs requiring running to the foodcup produced the OLE but also reversed the first-trial results. Results were discussed in terms of Spence's conception of the role of $r_{g}$ in incentive and frustration.

The purpose of this study was to examine two predictions which follow from the Hull-Spence conception of classical conditioning of the fractional anticipatory goal response $\left(r_{\mathrm{g}}\right)$ as the mechanism underlying the development of incentive motivation $(K)$ and conditioned frustration $\left(r_{f}\right)$. These predictions are, first, that first-trial acquisition performance will be an increasing function of the number of rewarded direct placements (DPs) in the goalbox prior to runway training (Spence, 1956), and, second that resistance to extinction tested after a small number of training trials will be an inverse function of the number of rewarded DPs preceding. runway training (Theios \& Brelsford, 1964).

Separate confirmations of both predictions have been reported. Earlier attempts to confirm the first prediction were not very successful (Stein, 1957; Swift \& Wike, 1958; Gonzalez \& Diamond, 1960), but Senkowski, Porter, \& Madison (1968) found that first-trial performance in a straight runway was faster for Ss given 60 rewarded. DPs prior to runway training, compared to those given only 10 rewarded DPs. There was no difference produced by 60 vs 10 nonrewarded DPs. The effect was most evident for performance measures near the goal, consistent with Spence's (1956) hypothesis that the conditioning of $r_{\mathrm{g}}$ progresses backward from the gaal through stimulus generalization.

Confirmation of the second prediction was obtained by Theios \& Brelsford (1964). As part of a study of the overlearning-extinction effect, they compared resistance to extinction following 10 reinforced training trials for $\mathrm{Ss}$ given either 0 or 50 rewarded DPs prior to runway training. Resistance to extinction was less following the rewarded DPs. They explained these results by assuming

* Supported by grants from the University of Wisconsin-Milwaukee Graduate School, and National Science Foundation Undergraduate Research Grant No. GY-2639. that resistance to extinction was a decreasing function of number of appetitive rewards experienced at the goal. This follows from the Spence (1960) and Amsel (1967) competing-response-frustration view of extinction, which assumes that $r_{f}$ is an increasing function of $r_{g}$.

Thus it appears that the same experimental procedure, prior rewarded DPs, can both enhance initial acquisition performance and decrease resistance to extinction. Experiment 1 these effects with the same Ss.

$$
\text { EXPERIMENT } 1
$$$$
\text { Subjects }
$$
rats, approximately 90 days old, were used. They were assigned randomly to four groups of $11 \mathrm{Ss}$, differentiated by whether they received 10 or 60 DPs prior to runway training and whether or not the DPs were rewarded.

\section{Apparatus}

A 90-in. runway, including a 12-in. startbox and 18-in. goalbox, was used. All sections of the runway were black, had a clear plastic top, and were 5 in. high. The start and run sections were $3 \mathrm{in}$. wide, and the goal section was $4^{1 / 2}$ in. wide. Start time was recorded from the dropping of the start door to 12 in. into the runway. Run time was measured over the following $46^{1 / 2}$ in., ending at the entrance to the goalbox. Goal time was measured over the following $18 \mathrm{in}$. to a point directly over the foodcup and $1 \frac{1 / 2}{\text { in. from the }}$ rear wall of the goalbox. A dropping door at the entrance to the goalbox prevented retracing. All times were measured with 1/100-sec S-1 timers actuated by photorelays. The floor of the alley and goalbox were divided into 263 -in. segments, each pivoted so that $S$ 's weight closed a microswitch which actuated a channel on an Esterline-Angus event recorder. The Esterline-Angus record served as an indication of S's location in the alley and goalbox at all times and allowed an objective measure of avoidance responses, defined as retraces in the alley (cf. Ison, 1962). was conducted to examine both of

Forty-four male Holtzman albino
Procedure

All Ss were maintained throughout the experiment on a daily feeding schedule limited to $15 \mathrm{~g}$ of wet mash, containing approximately $7 \mathrm{~g}$ of dry food. During the first 7 days of deprivation, Ss were placed in the carrying cages used throughout the experiment and given $10 \mathrm{~min}$ of exploration in the runway, two Ss at a time, with the start and goalbox doors open. On Day 9 each $\mathrm{S}$ was given two nonrewarded runway trials. During these trials, and on all later runway trials, Ss were released from the startbox when they oriented toward the start door. The goalbox door was closed as soon as $S$ entered the goalbox. In the group designations below, the numbers refer to number of DPs and the letters to whether these DPs were rewarded or not. On Days 10-21, Ss in Groups 10R and $10 \mathrm{NR}$ received five DPs in the goalbox daily. The Ss in Groups 10R and $10 \mathrm{NR}$ were maintained on the deprivation schedule through Day 17 and were pretrained on Days 18 and 19. These Ss received their DPs on Days 20 and 21.

On DP trials all Ss were placed directly over the foodcup, a glass coaster, whether they were fed or not. The $\mathrm{R}$ groups were allowed 30 sec to consume $.7 \mathrm{~g}$ of wet mash, while the NR groups received a similar amount of time in the goalbox with the coaster empty. Approximately $5 \mathrm{~min}$ after return to their carrying cages, the $\mathrm{NR}$ Ss were fed $.7 \mathrm{~g}$ of wet mash for 30 sec. The $R$ Ss had an empty coaster in their carrying cages for $30 \mathrm{sec}$, approximately $5 \mathrm{~min}$ after each trial. Water was available for Ss at all times in the carrying cages. A minimum of $11 \mathrm{~min}$ elapsed between trials for each $S$ throughout the experiment.

On Day 22 all Ss were given four reinforced running trials and five such trials on Day 23. On Day 24 all Ss received one reinforced running trial followed by four extinction trials. From Day 25 on, Ss were given five extinction trials daily, until they exceeded the extinction criterion of more than 60 sec to run from startbox to goalbox entrance.

\section{Results}

Response speeds for the rewarded DP groups on the first acquisition trial as a function of prior rewarded DPs were examined first. These are shown in the upper portion of Table 1 . The predicted superiority of the $60 \mathrm{R}$ group over the $10 \mathrm{R}$ group was most evident for goal speed, $t(20)=2.25, p<.05$, and less evident for run speed, $\mathrm{t}(20)=1.73, \mathrm{p}<.10$. The difference was not significant for start speed, $\mathrm{t}(20)<1.0$, although it was in the predicted direction. As expected, the $60 N R$ and $10 \mathrm{NR}$ control groups did 
Table 1

Mean Response Speeds in Ft/Sec for Acquisition Trials of Rewarded DP Groups in Experiments 1 and 3

\begin{tabular}{|c|c|c|c|c|c|c|}
\hline \multirow{3}{*}{$\begin{array}{c}\text { Experiment } \\
\text { and } \\
\text { Group }\end{array}$} & \multirow{2}{*}{\multicolumn{2}{|c|}{$\frac{\text { Start Speed }}{\text { Trials }}$}} & \multirow{2}{*}{\multicolumn{2}{|c|}{$\frac{\text { Run Speed }}{\text { Trials }}$}} & \multirow{2}{*}{\multicolumn{2}{|c|}{$\frac{\text { Goal Speed }}{\text { Trials }}$}} \\
\hline & & & & & & \\
\hline & 1 & $1-10$ & 1 & $1-10$ & 1 & $1-10$ \\
\hline $\begin{array}{l}1-60 R \\
1-10 R\end{array}$ & $\begin{array}{r}1.27 \\
.83\end{array}$ & $\begin{array}{l}2.77 \\
1.56\end{array}$ & $\begin{array}{l}1.73 \\
1.24\end{array}$ & $\begin{array}{l}3.03 \\
2.40\end{array}$ & $\begin{array}{l}.43 \\
.28\end{array}$ & $\begin{array}{r}1.11 \\
.84\end{array}$ \\
\hline $\begin{array}{l}3-60 R \\
3-10 R\end{array}$ & $\begin{array}{l}.85 \\
.89\end{array}$ & $\begin{array}{l}2.25 \\
2.53\end{array}$ & $\begin{array}{l}1.62 \\
1.83\end{array}$ & $\begin{array}{l}3.11 \\
\mathbf{3 . 4 3}\end{array}$ & $\begin{array}{r}.53 \\
1.00\end{array}$ & $\begin{array}{l}1.25 \\
1.44\end{array}$ \\
\hline
\end{tabular}

not differ significantly on any performance measure.

Response speeds over all 10 acquisition trials, shown for the rewarded DP groups in the upper portion of Table 1 , were analyzed in a 2 by 2 analysis of variance over the R-NR and $10-60$ factors. Neither start nor run speed yielded any significant differences, while goal speed yielded a significant number of DPs effect, $F(1,40)=5.51, p<.025$, and $R$ vs $N R$ placements effect, $F(1,40)=17.8$, $p<.001$. Significant simple effects of reinforcement at both 10 DPs, $\mathrm{F}(1,40)=5.66, \mathrm{p}<.05$, and $60 \mathrm{DPs}$, $\mathrm{F}(1,40)=12.86, \mathrm{p}<.001$, indicated that reinforced DPs led to superior goal speed. The simple effects of number of DPs showed that $60 \mathrm{R}$ Ss ran faster than $10 \mathrm{R}$ Ss, $F(1,40)=5.13$, $\mathrm{p}<.05$, but that $60 \mathrm{NR}$ vs $10 \mathrm{NR}$ DPs did not significantly affect goal speed. Evidently, the incentive effect of rewarded DPs persists through 10 acquisition trials, at least for goal speed. These findings are in agreement with Senkowski et al (1968).

In extinction the primary interest was in a comparison of the $10 R$ and $60 \mathrm{R}$ groups, each of which had 10 reinforced acquisition trials, but 20 and 70 total reinforcements, respectively. The mean number of trials to extinction for these groups are shown in the left panel of Fig. 1. The predicted superiority in trials to extinction of the $10 \mathrm{R}$ group was not found. Rather, the $60 \mathrm{R}$ group was significantly more resistant to extinction, $t(20)=2.39, \quad p<.05$. Further, $S s$ in the $10 \mathrm{R}$ group made their first avoidance responses on earlier trials than did the $60 \mathrm{R}$ Ss, with means of 5.2 and 10.0 , respectively, $\mathrm{t}(20)=2.19, \mathrm{p}<.05$. Groups $10 \mathrm{NR}$ and 60NR, whose DPs were not rewarded, did not differ -ignificantly in trials to extinction or trials to the first avoidance response.

\section{EXPERIMENT}

The first running trial results of Experiment 1 agreed with those of Senkowski et al (1968) and with Spence's (1956) conception of how the classical conditioning of $r_{g}$ transfers to instrumental performance.
However, the extinction results of Experiment 1 disagreed with those of Theios \& Brelsford (1964) and were counter to the frustration interpretation of extinction used by these authors and others. On the chance that the unexpected extinction results in Experiment 1 were due to artifacts of apparatus or general procedures, Experiment 2 was conducted to see if the overlearning-extinction effect could be reproduced with conventional running trials, i.e., without DPs in the goalbox. Two groups were given the same total numbers of reinforcements as Groups $10 \mathrm{R}$ and $60 \mathrm{R}$ in Experiment 1, but these Ss ran the runway for all their 20 or 70 reinforcements.

Subjects and Apparatus

Twenty-two male Holtzman albino rats, approximately 90 days old, were used; they were assigned randomly to two groups of 11 Ss. The apparatus was the same as that in Experiment 1.

\section{Procedure}

Deprivation and pretraining through Day 9 were the same as in Experiment 1. The 70R group was given four reinforced running trials on Day 10 and five trials daily through Day 23. Group 20R was given four reinforced running trials on Day 20 and five trials daily on Days 21-23. Both groups were given one reinforced

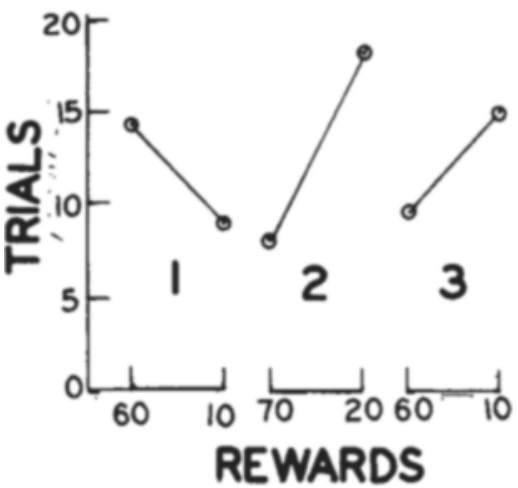

Fig. 1. Trials to extinction as a function of number of rewarded DPs in Experiments 1 and 3 , and number of rewarded running trials in Experiment 2. trial on Day 24, followed by four extinction trials. From Day 25 on, Ss were given five extinction trials daily until they reached the same 60-sec extinction criterion as in Experiment 1. All Ss were reinforced with $.7 \mathrm{~g}$ of wet mash and had been on deprivation for the same number of days at the beginning of extinction. All other details of procedure were the same as in Experiment 1.

Results

The mean start, run, and goal speeds over the final 10 acquisition trials for Groups $70 \mathrm{R}$ and $20 \mathrm{R}$ in feet/second were 4.93 vs $2.97,4.15$ vs 3.69 , and 2.43 vs 1.65 , respectively. The $70 \mathrm{R}$ group was significantly faster than the 20R group for all three measures, $\mathrm{t}(20)=2.69, \mathrm{p}<.02 ; 2.22, \mathrm{p}<.05 ;$ and $3.85, p<.001$, respectively.

As shown in the center panel of Fig. 1, the overlearning-extinction effect was obtained. Group 70R reached the extinction criterion in significantly fewer trials than did the 20R group, $\mathrm{t}(20)=3.84, \mathrm{p}<.002$. The mean number of trials to the first avoidance response for the $70 \mathrm{R}$ group (5.5) was earlier than for the $20 \mathrm{R}$ group (8.3), but this difference was not significant.

\section{EXPERIMENT 3}

The results of Experiment 2 showed that the overlearning extinction effect could be produced with conventional running trials using the present apparatus and procedures, suggesting that the results of Experiment 1 were not due to some artifact. The difficulty still remained in reconciling the apparent inconsistency between the incentive effect of rewarded DPs on first-trial running performance in Experiment 1 and the absence of a frustration effect during extinction.

A possible reason for the absence of a frustration effect during extinction in Experiment 1 was suggested by the results of Trapold \& Doren (1966). In a study of the effects of partially reinforced DPs between acquisition and extinction, they found that DPs directly over the foodcup did not increase resistance to extinction. Rather, it was necessary to have $\mathrm{Ss}$ run some distance in the goalbox to the foodcup on DP trials for the partial reinforcement effect to occur, a procedure which had been used successfully by Theios \& Polson (1962) in a related study. Trapold and Doren suggested that the conditioning and generalization of $r_{f}$ to running in the alley involves the response-produced stimulation of the running response itself, as well as the visual and other external cues of the runway. If the effective stimulus complex involves these response-produced stimuli, running 
DPs should more adequately transfer $r_{f}$ from the goalbox to the runway.

To examine the possibility that inadequate transfer of $r_{g}$ from $D P$ to running behavior was the cause of the failure to obtain the predicted extinction results in Experiment 1, the experiment was replicated with one difference. During DPs, Ss were placed some distance from the foodcup rather than directly over it.

\section{Subjects, Apparatus, and Procedure}

Forty male Holtzman albino rats, approximately 110 days old, were used. All details of apparatus and procedure were exactly the same as in Experiment 1 , except that Ss were placed $12 \mathrm{in}$. from the foodcup on DP trials and allowed to run to the cup.

\section{Results}

The extinction results were opposite to those of Experiment 1. As shown in the right panel of Fig. 1, the overlearning-extinction effect was obtained, with the $60 \mathrm{R}$ group extinguishing faster than the $10 \mathrm{R}$ group, $t(18)=2.16, p<.05$. There was no significant difference between the NR groups. Following Friedman's (1968) suggestion, $r_{m}$ was calculated as a measure of the experimental effect of rewarded DPs upon trials to extinction in Experiments 1 and 3 , yielding $\mathrm{r}_{\mathrm{m}}=.47$ and .45 , respectively. The magnitudes of effect were quite similar, but in opposite directions. Further, the 60R group in Experiment 3 tended to make first avoidance responses on earlier trials than the $10 \mathrm{R}$ group. The means were 6.0 and 11.2 , respectively, $\mathrm{t}(18)=2.63, \mathrm{p}<.02$. On this measure, $r_{m}=.44$ and .53 for Experiments 1 and 3 , showing a somewhat larger effect, in the opposite direction, for Experiment 3. Clearly, DPs which required running to the foodcup produced the predicted inverse relation between number of rewarded DPs and resistance to extinction, while the DPs over the foodcup did not.

However, the first acquisition trial performances of the $60 \mathrm{R}$ and $10 \mathrm{R}$ groups were also opposite to those in Experiment 1. As shown in Table 1, the $10 \mathrm{R}$ group ran faster than the $60 \mathrm{R}$ group, a difference most evident for goal speed, $\mathrm{t}(18)=2.14, \mathrm{p}<.05$, and less evident for run speed, $t(18)=1.32$, p slightly greater than .20. The start speed difference was small, $t(18)<1.0$, but in the same direction. Comparisons of the experimental effects in Experiments 1 and 3 yielded $r_{m}=.45$ for goal speed in both experiments, and $r_{m}=.36$ and .30 , respectively, for run speed. The magnitudes of effect were therefore quite similar in the two experiments, but in opposite directions. It appears that placing Ss some distance from the foodcup reversed the incentive motivation effect upon first-trial performance compared to DPs directly over the foodcup.

As shown in Table 1, the pattern of performance over all 10 acquisition trials was consistent with performance on the first trial. However, the superiority of the $10 \mathrm{R}$ group over the $60 \mathrm{R}$ group was not significant over all 10 acquisition trials for any response measure.

\section{DISCUSSION}

The results of Experiments 1 and 3 showed that an increase in the number of rewarded DPs directly over the foodcup increased both first-trial acquisition performance and resistance to extinction, while an increase in the number of rewarded DPs which required Ss to run some distance to the foodcup produced opposite results for both measures. If the conditioning and generalization of $r_{g}$ is the mechanism underlying both $K$ and $r_{f}$, one would think that an experimental operation which enhances the effect of $r_{g}$ during extinction, as the running DPs presumably did in Experiment 1, would also enhance its effect upon first-trial acquisition performance, or at least not reduce its effect. Yet, the acquisition results in Experiments 1 and 3 were opposite.

One possible explanation of this seeming contradiction lies in an examination of the behavior involved on a DP trial, which requires $S$ to run to the foodcup. What is transferred to the runway on the first acquisition trial may not be simply running, but running a short distance and then either pausing or slowing. There could be at the same time, therefore, a conflict between a tendency to traverse the runway and a tendency to pause or slow down a short distance into the runway. The apparatus used in the present experiments was not capable of supplying a sufficiently detailed account of running speeds over short segments of the runway to permit a thorough test of this hypothesis. However, examination of the avoidance response data from Experiments 1 and 3 showed that on the first acquisition trial in Experiment 1, with DPs directly over the foodcup, three Ss from the $60 \mathrm{R}$ group retraced in the first 12 in. of the runway and none in the later segments. In Experiment 3, with DPs $12 \mathrm{in}$. from the foodcup, none of the Ss from the $60 \mathrm{R}$ group retraced in the first 12 in., but four of them did in the later segments. Fisher's exact probability test for this 2 by 2 contingency yielded $p=.029$, so this result does not support the hypothesis that DPs away from the foodcup tend to condition a short run followed by a pause. This evidence is indirect, however, and it may be worthwhile to examine the effect of rewarded DPs upon runway performance by means of a number of precise running speed measures throughout the length of the runway and goalbox.

The question also remains as to why Theios \& Brelsford (1964) were able to get an overlearning-extinction effect of rewarded DPs directly over the foodcup, which was not obtained in the present study. While there were a number of differences in details between these two experiments, none of them provides an obvious answer. The present results, together with those of Trapold \& Doren (1966) suggest that the effects of rewarded DPs may be sensitive to differences in locating Ss during DPs, and that simplistic views of the conditioning of $r_{g}, K$, and $r_{f}$ are not sufficient to explain the effects.

\section{REFERENCES}

AMSEL, A. Partial reinforcement effects on vigor and persistence. In $K$. W. Spence and J. T. Spence (Eds.), The psychology of leaming and motivation. Vol. 1. New York: Academic Press, 1967.

FRIEDMAN, H. Magnitude of experimental effect and a table for its rapid estimation. Psychological Bulletin, 1968, 70. 245-251.

GONZALEZ, R. C., \& DIAMOND, L. A. A test of Spence's theory of incentive motivation. American Joumal of Psy chology , 1960, 73, 396-403.

ISON,J. R. Experimental extinction as a function of number of reinforcements. Journal of Experimental Psychology. 1962, 314-317.

SENOKOWSKI, P. C., PORTER, J. J., \& MADISON, H. L. Goal gradient effect of incentive motivation (K) manipulated through prior goal box placements. Psychonomic Science, 1968, 11, 29-30.

SPENCE, K. W. Behavior theory and conditioning. New Haven: Yale University Press, 1956.

SPENCE, K. W. Behavior theory and learning. New York: Prentice-Hall, 1960

STEIN, L. The classical conditioning of the consummatory response as a determinant of instrumental performance. Joumal of Comparative \& Physiological Psychology. $1957,50,269-278$.

SWIFT, C. F., \& WIKE, E. L. A test of Spence's theory of incentive motivation. Psychological Record, 1958, 8, 21-25.

THEIOS; J. \& BRELSFORD J. $O$ verlearning-extinction effect as an incentive phenomenon. Journal of Experimental Psychology, 1964, 67, 463-476.

THEIOS, $J, \&$ POLSON, P. Instrumental and goal responses in nonresponse partial reinforcement. Journal of Comparative \& Physiological Psychology, 1962, 55 , 987-991.

TRAPOLD, M. A., \& DOREN, D. G. Effect of noncontingent partial reinforcement on the resistance to extinction of a running response. Journal of Experimental Psychology, 1966, 71 429-431. 